\title{
Correlations of Hormone Receptors (ER and PR), Her2/neu and p53 Expression in Breast Ductal Carcinoma Among Yemeni Women
}

\author{
Hussain Gadelkarim Ahmed ${ }^{1}{ }_{*}$, Mohammed Ali Al-Adhraei $^{2}$ and Abdullah Kasim Al-Thobhani ${ }^{3}$ \\ ${ }^{I}$ Department of Histopathology and Cytology, Yemen. Faculty of Medical laboratory Sciences, University of Khartoum; \\ Sudanese Cancer Foundation, Khartoum, Sudan; ${ }^{2}$ National Oncology Center, Al-Jumhory Teaching Hospital, Sana'a, \\ Yemen ${ }^{3}$ Department of pathology, Faculty of Medicine, Sana'a University, Yemen
}

\begin{abstract}
Aims: The purpose of this study was to determine if any relationship exists between Estrogen Receptor (ER), Progesterone Receptor (PR), Her2/neu, P53, and clinicopathological factors in female breast ductal carcinoma. Materials and Methods: One hundred and thirty seven (IDC=124, NIDC=13) ductal carcinomas were clinicopathologically and immunohistochemically analyzed and compared with 20 control cases of benign breast lesions in which assessment of Her2/neu, ER, PR, and P53 has been performed, prospectively. Chi-square analysis was then used to correlate the above observations. Results: The overall immunoexpression of ER, PR, Her2/neu and P53 were 43.8\%, 27\%, 30.6\% and 48.9\%, respectively, of the 137 ductal carcinomas. A significant Positive association between ER or PR expression with lymph node involvement was found ( $\mathrm{p}=0.004, \mathrm{p}=0.022$ respectively), while $\mathrm{p} 53$ was found to be negatively associated with lymph nodes involvement ( $\mathrm{p}=0.03,0.02$, respectively). P53 also associated negatively to lymph node status $(\mathrm{P}=0.03)$ and positively with borderline tumor grade $(\mathrm{p}=0.03)$. Conclusion: There are high rates of positive expression of ER, PR, Her2/neu and P53 among Yamani women with breast ductal carcinoma.
\end{abstract}

Keywards: ER, PR, Her2/neu and p53, Breast Carcinoma, Yemeni.

\section{INTRODUCTION}

Breast cancer has a great impact in women's health. In Yemen, it is the second most common malignant neoplasia, but it is the leading cause of death among women. Most of these cases were ductal carcinoma (Invasive ductal carcinoma (IDC) or Non-invasive ductal carcinoma (NIDC)) [1].

Invasive breast cancer is still the most common female malignancy worldwide and more than 1 million women are diagnosed with breast cancer each year [2]. Currently, it is believed that the invasive carcinoma derives from an in situ component; because of its frequent coexistence and histologic similarity [3]. This linear process would occur through several steps, where the normal epithelium modifies to ductal carcinoma in situ (DCIS), progressing to invasive carcinoma and then metastasis [4].

It has been proposed that many parallel pathways may exist for the high and low-grade carcinoma, as well as, for the pure ductal carcinoma in situ (pDCIS), or to the DCIS associated with invasive ductal carcinoma (IDC) and to pure invasive carcinoma [5].

Different expression patterns for estrogen receptor alpha (ER- $\alpha$ ), progesterone receptor (PR), and epidermal growth factor receptor between high-grade DCIS and DCIS/IDC, have been identified, suggesting that at least some pDCIS is molecularly distinct from DCIS +IDC, but these differences

*Address correspondence to this author at the University of Khartoum, 102, Faculty of Medical Laboratory Sciences, Khartoum, Sudan;

Tel: +249912698998; Fax: +249155130423;

E-mails: Hussain@uofk.edu; hussaingad1972@yahoo.com. were not seen without the cytokeratin subtypes [6]. The expression patterns of ER- $\alpha$, PR, HER-2/neu, and EGFR are markedly different in different cell origin subtypes of both high grade and non-high grade DCIS, suggesting that cell origin subtypes as well as, nuclear grade contribute to the biological and molecular heterogeneity of DCIS [7].

The aims of this study were to initiate the establishment of a data base about the hormone receptors, HER2 and p53 incidences and to evaluate the association between these markers and other pathological factors in females diagnosed with breast cancer in Yemen.

\section{MATERIALS AND METHODS}

One hundred and fifty seven formalin-fixed, paraffinembedded tissue block samples from the breast lesions were investigated. These included 124 cases of invasive ductal carcinomas, 13 in-situ ductal carcinomas and 20 cases of benign breast lesions. Data related to the studied subjects were retrieved from Oncology Center, Al-Jumoury Teaching Hospital, Sana'a; Yemen. The benign lesions included, Fibroadenoma, fibrocystic changes of the breast and mastitis constituting, $10(50 \%), 5(25 \%)$ and 5(25\%), respectively.

All biopsies were obtained from females with breast lesions, their ages ranging from 16 to 80 years with mean age of 43.75 years old, among whom 137/157 (87.3\%) had primary breast cancer, their ages ranging from 21 to 80 years with a mean age of 46 years old (ascertained as cases). The remaining 20 individuals were selected from patients with benign breast tumors (ascertained as internal controls), their ages ranged from 16 to 45 years, with a mean age of 28 years. 
Table 1. Distribution of Ductal Carcinoma by Clinicopathological Features

\begin{tabular}{|c|c|c|}
\hline Clinicopathological Features & Frequency & Percent \\
\hline \multicolumn{3}{|c|}{ Histological type (available for $137(100 \%)$ ) } \\
\hline IDC & 124 & 90.5 \\
\hline Non IDC & 13 & 9.5 \\
\hline Total & 137 & 100 \\
\hline \multicolumn{3}{|c|}{ Tumor size (available for $106(77.4 \%)$ ) } \\
\hline$<2 \mathrm{~cm}$ & 7 & 6.6 \\
\hline $2-5 \mathrm{~cm}$ & 74 & 69.8 \\
\hline$>5 \mathrm{~cm}$ & 25 & 23.6 \\
\hline Total & 106 & 100 \\
\hline \multicolumn{3}{|c|}{ Tumor grade(available for $87(63.5 \%)$ ) } \\
\hline Grade I & 22 & 25.3 \\
\hline Grade II & 48 & 55.2 \\
\hline Grade III & 17 & 19.5 \\
\hline Total & 87 & 100 \\
\hline \multicolumn{3}{|c|}{ Lymph node status(available for $81(59.1 \%)$ ) } \\
\hline Positive & 61 & 75.3 \\
\hline Negative & 20 & 24.7 \\
\hline Total & 81 & 59.1 \\
\hline
\end{tabular}

Sample processing: Serial sections on poly-L-lysinecoated slides for immunohistochemistry (IHC) and one section on a regular slide for Hematoxylin and Eosin (H\&E) procedure were prepared from each case. The immunohistochemistry staining was performed as described previously $[8$, 9]. Slides were heated overnight at $56^{\circ} \mathrm{C}$, followed by deparaffinization through graded ethyl alcohols and rehydration to the aqueous buffer. Before immunostaining with antibodies, the tissues were treated with $10 \mathrm{mM}$ sodium citrate buffer $\left(\mathrm{pH}\right.$ 6.0) at $100 \mathrm{C}^{0}$ for 15 minutes for antigenic retrieval. The samples were then incubated in $0.3 \%$ hydrogen peroxide (Merk, Germany) in methanol for 30 minutes to inhibit endogenous Peroxidase activity, then washed 3 times with phosphate buffered-saline (PBS). For blocking of nonspecific background staining, horse normal serum (DAKO, Denmark) diluted in phosphate buffer (PBS) was used, the slides then were rinsed in distilled water DW $2 \times 5$ minutes in PBS. Primary antibodies were incubated for 8 hours in a humidity chamber using the following dilutions: p53 (clone DO-7, titer 1:50, Dako, Denmark), and HER-2/neu (titer 1:50, Dako, Denmark), ER (clone 1D5, Dako, Denmark) PR (clone PgR 636, Dako, Denmark), was performed by applying the Avidin-Biotin-Peroxidase complex method. After rinsing the sections in two changes of PBS for 5 minutes in each, then secondary antibody (LSAB2, DAKO) was incubated for 30 minutes in the same chamber. Detection of the primary antibody was obtained using the Strepto ABC, LSAB2 system (DAKO) according to the manufacture in- structions. The sections were counter stained using Hematoxylin, dehydrate using ethyl alcohol, cleared using xylene and mounted in DPX then examined with light microscope. All sections were performed at the same time and submitted to standard methods. Known positive and negative cases were used as external controls. Three investigators have evaluated the sections independently. Positive expression for each tumor marker was defined as in the literature: ER, and PR, were considered positive when $>10 \%$ of the nuclei were stained in 10 high power field (HPF) [10, 11]. The HER$2 /$ neu was considered negative when had score 0 and +1 , and positive with score +2 and +3 . To be considered as $+2,+3$ the cellular membrane should be completely stained in more than $10 \%$ of the tumor cells. Cells without staining, or with weak staining in part of the cell membrane and in less than $10 \%$ of the tumor cells were considered negative [12].

P53 was considered positive when $>5 \%$ of the nuclei were stained in $10 \mathrm{HPF}$ [13]. Regardless to the consideration of the positivity, overall expression was further evaluated as follows: The stained slides were examined by light microscopy and graded as follows: "negative" (-) indicates absence of brown precipitate in cells; the positives, including controls, were labeled as $(+)$ if there were a few $(<10 \%)$ scattered cells with precipitate; $(++)$ for large areas $(10-50 \%)$ of positivity; and $(+++)$ designated $50 \%$ to $100 \%$ positivity.

\section{ETHICAL CONSENT}

The study was submitted and approved by the Faculty Research Board of Sudan University for Science and Technology in collaboration with National Oncology Center, at Al-Jumhory Teaching Hospital, Sana'a, and Yemen. Sample size was calculated based on the proportions between samples, having the following parameters: a proportion of $65 \%$ of positive cases $( \pm 8 \%)$ and a $95 \%$ confidence interval. This calculation yielded a minimum of 137 patients.

\section{STATISTICAL ANALYSIS}

For all statistical analyses, the SPSS system for personal computer was used, and $\mathrm{P}$ values of 0.05 or less were regarded as statistically significant. Kendall's W Test was for coefficient of concordance.

\section{RESULTS}

The clinic-pathological features of the cases were shown in Table 1. Histological type (IDC and NIDC), tumor size, tumor grade and lymph node status were available in 137 (IDC=124 and NIDC=13), 106, 87 and 81 of the cases, respectively.

Her2/neu and P53 markers used lacked expression in normal epithelium. Therefore, normal squamous epithelium served as the control for their analyses. The results presented here were based on the expressions of the markers in the lesions.

Table 2 and Fig. (1) summarize the positive expression of different markers in all cases of ductal carcinoma: 60 (43.8\%) positive for ER, 37 (27\%) for PR, 42 (30.6) \% for Her2/neu and 67 (48.9) \% for p53. The P values of the overall expression of ER, PR, Her2/neu and P53 in cases compared with controls were $0.16,0.01,0.001$ and 0.0001 
Table 2. Expression of ER, PR, Her2/neu and P53 in Cases

\begin{tabular}{|c|c|c|c|c|c|}
\hline Marker & \multicolumn{2}{|c|}{ Positive } & \multicolumn{2}{c|}{ Pegative } & Percent \\
\hline Cases (137) & Frequency & Percent & Frequency & 56.2 & 0.16 \\
\hline \hline ER & 60 & 43.8 & 77 & 73 & 0.01 \\
\hline PR & 37 & 27 & 100 & 69.4 & 0.001 \\
\hline Her2/neu & 42 & 30.6 & 70 & 51.1 & 0.0001 \\
\hline P53 & 67 & 48.9 & 95 & & \\
\hline
\end{tabular}

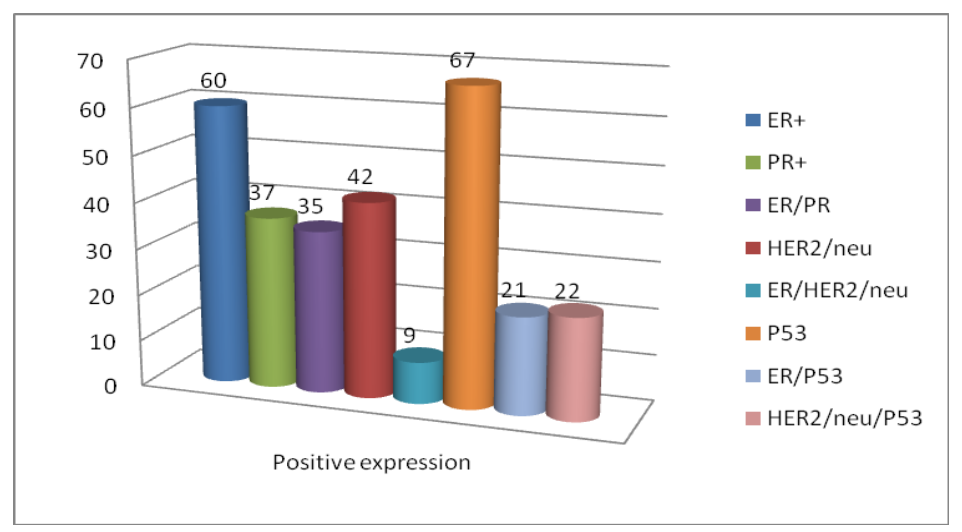

Fig. (1). Description of immunohistochemical positive expression and correlation of ER, PR, HER2/neu and P53 markers.

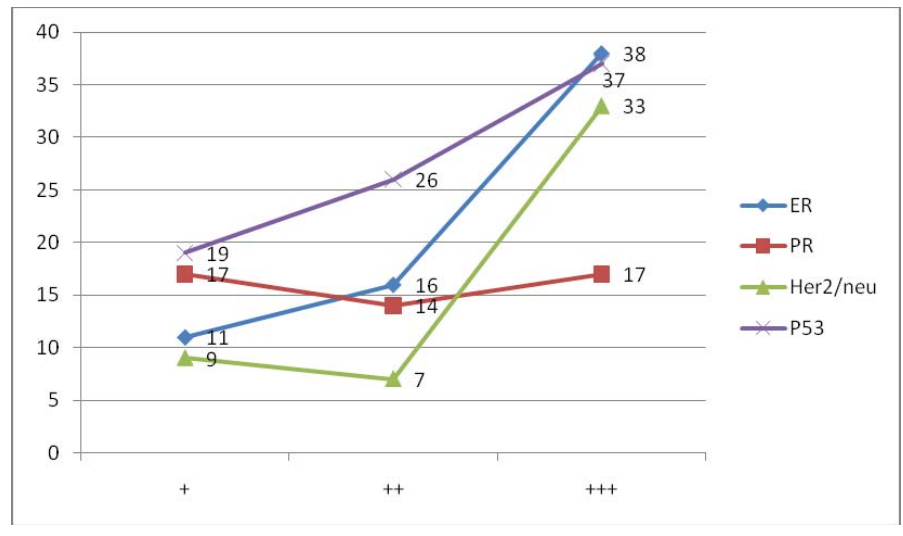

Fig. (2). Description of IDC by the level of immunohistochemical expression of ER, PR, HER2/neu and P53 markers.

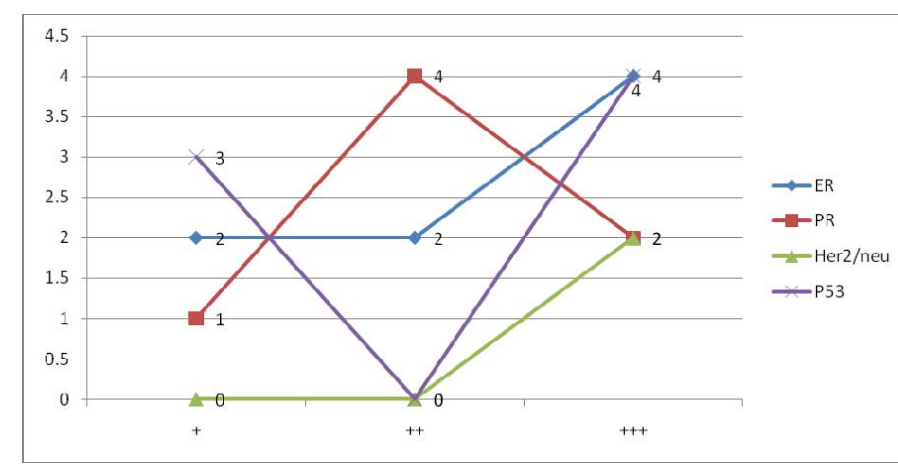

Fig. (3). Description of NIDC by the level of immunohistochemical expression of ER, PR, HER2/neu and P53 markers.

respectively. Positive correlations of immunostaining of ER/PR+, ER/HER2/neu+, ER/P53+ and HER2/neu/P53+, were identified in $35,9,21$ and 22 of the cases respectively, as shown in Fig. (1). Kendall's Coefficient of Concordance, showed mean ranks of, 2.27, 2.53, 2.82, 2.37 for ER, PR, Her2/neu and p53, respectively.
Figs. $(2,3)$ show the description of IDC and NIDC with various levels of immunohistochemical expression. For ER, $\mathrm{PR}, \mathrm{Her} 2 /$ neu and p53, it demonstrates that 38, 17,33 and 37 of +++ in IDC, respectively; and 4, 2, 2 and 4 of in NIDC, respectively. (see photomicrographs, (1-4)). 
Table 3. The Levels of Positive Expression of ER by the Tumor Size and Tumor Grade

\begin{tabular}{|c|c|c|c|c|}
\hline \multirow[t]{2}{*}{ Level of ER Expression } & \multicolumn{3}{|c|}{ Tumor Size } & \multirow[t]{2}{*}{ Total } \\
\hline & $<2 \mathrm{~cm}$ & $2-5 \mathrm{~cm}$ & $5 \mathrm{~cm}$ & \\
\hline+ & 0 & 7 & 1 & 8 \\
\hline+++ & 2 & 26 & 8 & 34 \\
\hline Total & 4 & 39 & 14 & 55 \\
\hline ER & Grade I & Grade II & Grade III & Total \\
\hline+ & 1 & 3 & 4 & 8 \\
\hline++ & 5 & 5 & 1 & 11 \\
\hline+++ & 5 & 13 & 7 & 25 \\
\hline Total & 11 & 21 & 12 & 44 \\
\hline
\end{tabular}

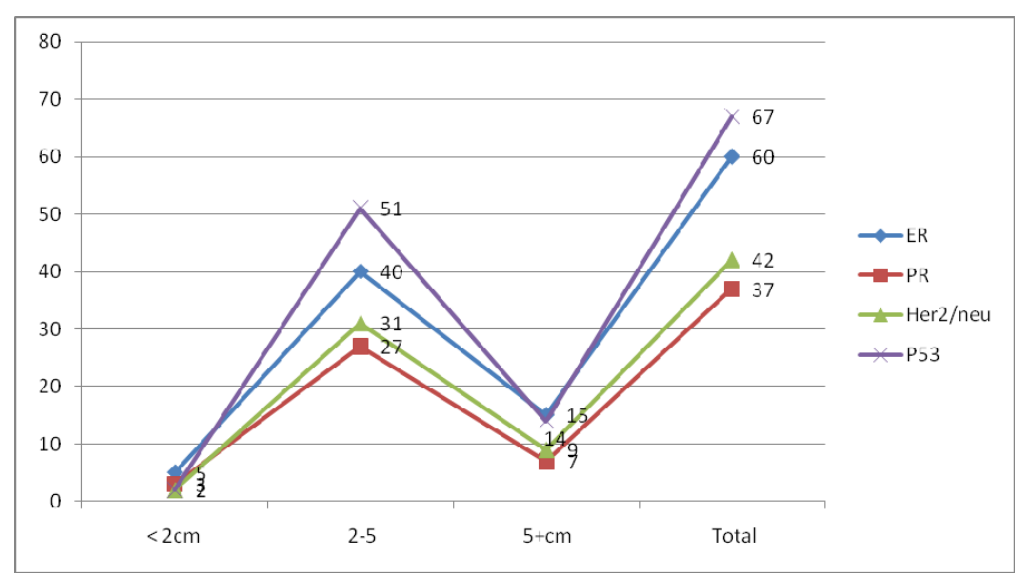

Fig. (4). Description of immunohistochemical expression of ER, PR, HER2/neu and P53 markers by tumor size.

Table. 4 The Levels of Positive Expression of PR by the Tumor Size and Tumor Grade

\begin{tabular}{|c|c|c|c|c|}
\hline \multirow[t]{2}{*}{ Level of PR Expression } & \multicolumn{3}{|c|}{ Tumor Size } & \multirow[t]{2}{*}{ Total } \\
\hline & $<2 \mathrm{~cm}$ & $2-5 \mathrm{~cm}$ & $5 \mathrm{~cm}$ & \\
\hline+ & 2 & 11 & 2 & 15 \\
\hline+++ & 1 & 11 & 4 & 16 \\
\hline Total & 4 & 30 & 11 & 45 \\
\hline PR & Grade I & Grade II & Grade III & Total \\
\hline+ & 3 & 2 & 5 & 10 \\
\hline++ & 1 & 7 & 2 & 10 \\
\hline+++ & 3 & 6 & 1 & 10 \\
\hline Total & 7 & 15 & 8 & 30 \\
\hline
\end{tabular}

The association between the levels of expression of ER and the tumor size, tumor grade and was summarized in Table 3. For ER, it demonstrates that $28.5 \%$ of,$+++ 28.5 \%$ of ++ and $0 \%$ of + in tumor size, $<2 \mathrm{~cm} ; 35 \%$ of,$+++ 8 \%$ of ++ and $9 \%$ of + in $2-5 \mathrm{~cm}$, and $32 \%$ of,$+++ 20 \%$ of ++ and $4 \%$ of + in $>5$. Although, these findings indicates that the level of expression of ER increases with the increase of tumor size and this was not found to be statistically significant $\mathrm{p}<0.06$.
For Tumor Grade I, Grade II and Grade III, the levels of expression of ER were; 5 (45.5\%), 13 (62\%), 7 (58\%), of +++, respectively. For lymph node positive status, the levels of expression of ER was found to increase in positive status and this was found to be statistically significant $\mathrm{P}<0.03$ (Fig. 5).

The relationships between the levels of expression of PR and the tumor size and tumor grade were summarized in Table 4. There is no statistically significant association be- 


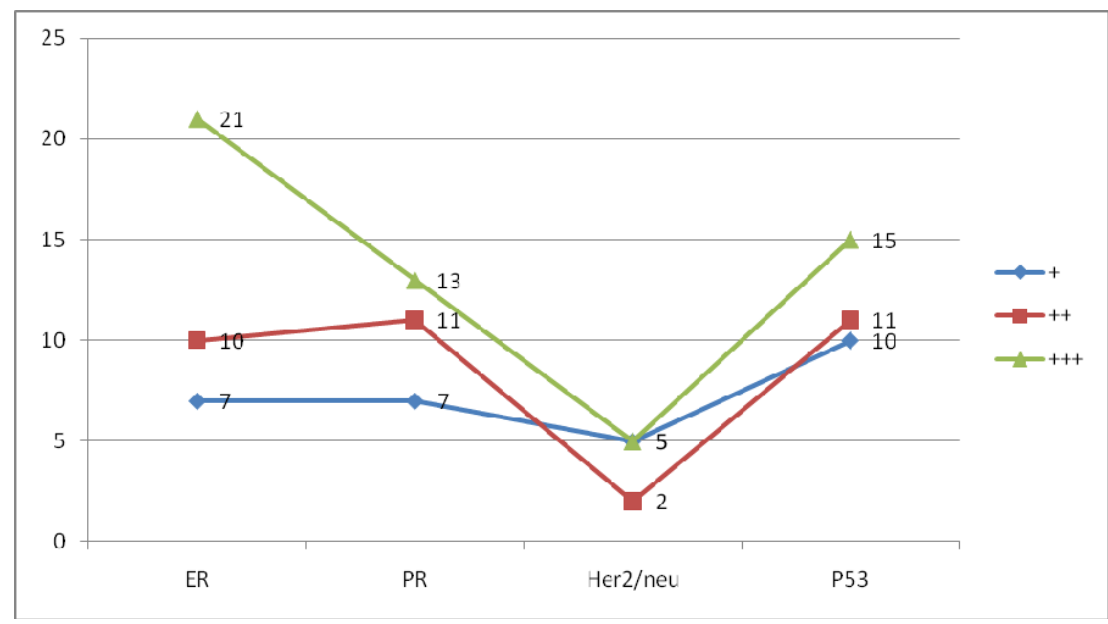

Fig. (5). Description of immunohistochemical levels of positive expression of ER, PR, Her2/neu, P53 by the lymph node positive status.

Table 5. The levels of Positive Expression of Her2/neu by the Tumor Size and Tumor Grade

\begin{tabular}{|c|c|c|c|c|}
\hline \multirow[t]{2}{*}{ Level of Her2/neu Expression } & \multicolumn{3}{|c|}{ Tumor Size } & \multirow[t]{2}{*}{ Total } \\
\hline & $<2 \mathrm{~cm}$ & $2-5 \mathrm{~cm}$ & $5 \mathrm{~cm}$ & \\
\hline+ & 1 & 4 & 2 & 7 \\
\hline++ & 1 & 3 & 0 & 4 \\
\hline+++ & 0 & 23 & 7 & 30 \\
\hline Total & 2 & 30 & 9 & 41 \\
\hline \multirow[t]{2}{*}{ Her2/neu } & \multicolumn{3}{|c|}{ Tumor Grade } & \multirow[t]{2}{*}{ Total } \\
\hline & Grade I & Grade II & Grade III & \\
\hline+ & 3 & 2 & 0 & 5 \\
\hline++ & 0 & 1 & 3 & 4 \\
\hline+++ & 5 & 13 & 4 & 22 \\
\hline Total & 8 & 16 & 7 & 31 \\
\hline
\end{tabular}

Table 6. The Levels of Positive Expression of ER by the Tumor Size and Tumor Grade

\begin{tabular}{|c|c|c|c|c|}
\hline \multirow[t]{2}{*}{ Level of P53 Expression } & \multicolumn{3}{|c|}{ Tumor Size } & \multirow[t]{2}{*}{ Total } \\
\hline & $<2 \mathrm{~cm}$ & $2-5 \mathrm{~cm}$ & $5 \mathrm{~cm}$ & \\
\hline+ & 0 & 10 & 5 & 15 \\
\hline++ & 2 & 16 & 5 & 23 \\
\hline+++ & 0 & 23 & 3 & 26 \\
\hline Total & 2 & 49 & 13 & 64 \\
\hline \multirow[t]{2}{*}{ P53 } & \multicolumn{3}{|c|}{ Tumor Grade } & \multirow[t]{2}{*}{ Total } \\
\hline & Grade I & Grade II & Grade III & \\
\hline+ & 5 & 8 & 2 & 15 \\
\hline++ & 3 & 11 & 4 & 18 \\
\hline+++ & 8 & 12 & 6 & 26 \\
\hline Total & 16 & 31 & 12 & 59 \\
\hline
\end{tabular}

tween levels of expression of PR and the tumor size or tumor grade, but the lymph node positive status showed statistically significant association $\mathrm{P}<0.02$ (Fig. 5).

The correlations between the levels of expression of Her $2 /$ neu and the tumor size, tumor grade were summarized in Table 5. The levels of expression Her2/neu didn't show any statistical significant difference with the tumor size or tumor grade or the lymph node positive status (Fig. 5).

The correlations between the levels of expression of P53 and the tumor size, tumor grade were summarized in Table 6. There is no statistically significant association between levels of expression of PR and the tumor size, or the lymph 
Table 7. Rates of Hormone Receptor Status of Breast Carcinoma in Some ASIAN and African Countries

\begin{tabular}{|c|c|c|}
\hline Country & ER & PR \\
\hline \hline Jordan [15] & $50.8 \%$ & $57.5 \%$ \\
\hline Iran [26] & $46.6 \%$ & $43.8 \%$ \\
\hline Srilanka [27] & $35.1 \%$ & $40 \%$ \\
\hline Tunisia [28] & $59.4 \%$ & $52.3 \%$ \\
\hline Egypt [29] & $62 \%$ & $42 \%$ \\
\hline Ghana [30] & $43.2 \%$ & $17.6 \%$ \\
\hline Pakistan [31] & $32.7 \%$ & $25.3 \%$ \\
\hline Sudan [32] & $90 \%$ & $77.5 \%$ \\
\hline
\end{tabular}

node positive status $(\mathrm{P}<0.06)$, Fig. 5), but tumor grade showed statistically significant association $\mathrm{P}<0.03$. However, the over all p53 expression has a significant negative association with lymph node involvement $(\mathrm{P}=0.03)$.

\section{DISCUSSION}

Breast cancer has a wide range of pathologic aspects and clinical behavior. Breast cancer is either the commonest or second commonest cause of cancer morbidity and mortality among women in developing countries [14]. The association between p53 expression and conventional pathological factors in breast cancer was already reported in previous studies that can be found in the literature. The interest in the study is the evaluation of this correlation in a poor studied specific and genetically homogenous population such as the Yemen women. In Yemen, more than $11.5 \%$ out of total 3400 patients under treatment in National Oncology Center (NOC) were females with breast cancer [1]. In those patients, the biology of breast cancer remains poorly understood while wide variety of molecular-based breast cancer prognostic factors and tumor markers have been studied in the western countries. The hormones receptor status and responsiveness of tumor to hormone therapy is an important parameter in breast cancer management and patient survival [15]. For example the possibility of treating breast cancer patients with zoledronic acid independently from their estrogen receptor status.[16] Therefore, the objective of this study was to compare the immunohistochemical expression of ER, PR, HER$2 /$ neu, and p53 in breast cancer classified as IDC and NIDC versus benign breast tumors.

Tumor markers: Tumor markers are molecules occurring in tissue that are associated with cancer and whose identification is useful in patient diagnosis and treatment or clinical management [17]. In this study, we compared the immunohistochemical expression of tumor markers (ER, PR, HER2/neu, P53) between breast ductal carcinoma (IDC+NIDC), without sub typing into low and high grade, as it was carried out by Mario et al., [18] versus benign breast lesions. Moreover, we compared the immunohistochemistry expression of these markers within the different breast tumors (ie, IDC, NIDC), as well as, with clinicopathological features of these lesions.

The expression of ER, PR, HER-2/neu and p53 revealed a high concordance, represented by the Kendall's Coefficient of Concordance (Kendall's $\mathrm{W}^{\mathrm{a}}=0.59$ ) with $\mathrm{P}$ value less than 0.001 . The similarities between the expressions of these tumor markers suggest that these tumors belong to the same cellular clone in different phases of their growth, and the in situ components may represent cells with a higher potential of malignancy. These findings are in agreement to those reported by Schuetz et al., [19] where they identified the similarities between the gene expression of the in situ and invasive components of the same tumor by using microarray hierarchical cluster analysis, and with others [20, 21].

Many studies in USA, Europe and Asia, [22-24] have reported differences in breast carcinoma sub-typing with hormones receptors status and HER2 by race and ethnicity.

$\boldsymbol{E R}$ and $\boldsymbol{P R}$ : The prevalence of hormones receptorpositive breast cancer in Asian countries has been found to be lower than those in the western world. However, as denoted in this study, the incidence rates of these markers particularly the ER and PR receptors, expressions were lower than what were reported in the literature from USA and Australia $(65 \%$ to $80 \%)$. [25, 26] However, these relatively lower ER and PR expressions in the present study were relatively consistent with the lower reported ranges in different Asian and African countries [15, 27-33], as shown in Table 7.

Her2/neu: In regard to Her2/neu the current results appear to be within the commonly reported rates of $20 \%$ to $30 \%$. [28, 30, 32, 34-36,] Less than $20 \%$ or more than $30 \%$ of HER2 over-expression was reported by many studies[31, 37, 38].

P53: Tumor suppressor gene (P53) is considered as a one of the important predictive markers in breast cancer as it gives good information about the resistant to some chemotherapeutic agents and can be used as specific prognostic factor in breast cancer [39]. In our series, the p53 expression was found in $48.2 \%$ of the cases examined. A proximately less than p53 expression rates reported by Al-Moundhri, et al., [35] (41.1\%), while Tammim, et al., [40] found that p53 positive expressions were present in $57.3 \%$ of primary breast cancer. However, the p53 expression in the present study is far from $27.6 \%$ which was demonstrated by Ihemelandu, et al., [41] and from $74.38 \%$ reported by Lu, et al., [36]. These differences may attribute to the demographic genetic variation and sample size used by different investigators.

ER/PR Co-expression: The over all co-expression of hormones receptors in this study were found as follow: $\mathrm{ER}+/ \mathrm{PR}+(39.41 \%), \quad \mathrm{ER}+/ \mathrm{PR}-(13.86 \%), \quad \mathrm{ER}-/ \mathrm{PR}+(0.72 \%)$ and ER-/PR-(45.98\%). One of the interested results in our study was that ER-/PR+ which found only in one case out of 137 malignant cases. Such findings was reported by Olivotto, et al., [42], they found only one case out of 192 with ER- have PR+ with weak positive immunostaining. These results were strongly challenged by [43] Colomer, et al., they reported $\mathrm{ER}+/ \mathrm{PR}+, \mathrm{ER}+/ \mathrm{PR}-, \mathrm{ER}-/ \mathrm{PR}+$, and ER-/PR- in $46 \%, 19 \%, 7 \%$ and $28 \%$, respectively. In another study, $63.9 \%$ of white American women with breast cancer were $\mathrm{ER}+/ \mathrm{PR}+, 12.8 \% \mathrm{ER}+/ \mathrm{PR}-, 3.6 \% \mathrm{ER}-/ \mathrm{PR}+$ and $19.8 \%$ ER-/PR- while among black American women $48.3 \%$ were $\mathrm{ER}+/ \mathrm{PR}+, 11.8 \% \mathrm{ER}+/ \mathrm{PR}-, 5 \% \mathrm{ER}-/ \mathrm{PR}+$ and $34.8 \%$ ER-/PR-[44]. 
One well defined subtype of breast cancer is characterized by lack of ER, PR and HER2 over-expression/ or amplification that's called TN tumors. It constitutes $10 \%$ to $20 \%$ of breast cancer. [45-47] In our cases, 39 (28.46\%) were triple negative and this value is high than that presented in the literature. TN prevalence was found to differ by race (29.3\% among African American women and 13\% among non- African American women)[48], while another study reported about the differences of TN with obesity $(29 \%$ obese vs $31 \%$ non-obese) [49].

ER/Her2/neu Co-expression: The inverse association between hormones receptors and HER2 leads to lower or absent hormone receptors in women with HER2 positive breast cancers. This is one of the reasons why women who over-express HER2 may be resistant to Tamoxifen [50]. Our results confirmed that the presence of ER and PR receptors (to some extent) in human breast cancer cell lines resulted in a strong reduction of HER2 protein over-expression. These findings are in agreement with other reports in the literature, which showed an inverse significant association between hormones receptors expression and HER2 over-expression [29, 34, 51]. Anim, et al., [52] didn't find any association between ER expression alone and HER2 over-expression.

ER/P53 Co-expression: With regard to ER and PR expression, p53 appears to be exhibit the same behavior of HER2. Our results showed a tendency of ER and PR hormones receptors positive tumors to be negative when associated with p53 expression. Most studies regarding this inverse association have focused on ER alone [53]. While other studies considered the negative association of ER and/ or PR expression with p53 over-expression $[35,54]$.

Her2/neu/P53 Co-expression: Despite our study didn't show any association between HER2 over-expression and p53 category, although, some studies have correlated HER2 over-expression with p53 [41,30], while other studies consistent with our findings $[35,38]$.

Markers and clinicopathological features: The IHC technique has an expanding prognostic role in determination of factors that affect clinicopathological features. Nevertheless, the results of this study showed different pattern of findings in respect to clinicopathological features. Hormone receptors contents had no noticeable relation with tumor grade, tumor size and histological type. In our findings the ER and PR receptors status have a positive association with lymph nodes involvement $(p=0.03$ and $p=0.02$, respectively). Similar findings were reported for PR only by Moradi-Marjaneh, et al., [55] while, Ayadi, et al., [29] didn't find any association between ER and PR expression and clinicopathological factors except a negative association with tumor grade. Furthermore, the associations of PR expression with other pathological factors were reported by Mohsin, et al., [56], while only association of ER and PR expression with tumor grade was reported by Adebamowo, et al., [37] in addition, to the findings by Lu, et al., [36], when, they demonstrated a negative association between the expression of hormones receptors and tumor size and tumor grade.

Some authors, as presented in our study, have suggested that HER-2 over-expression is not associated with clinicopathological factors. [35, 57] Furthermore, many authors re- ported that HER2 hasn't association with histological type [58, 59], tumor size [36, 38, 50], tumor grade [51, 59] and lymph nodes involvement $[38,58,59]$. In contrast, association of HER2 over-expression with tumor size [29, 34] tumor grade [30, 38, 55], lymph nodes involvement [60] and histological type [36] were reported.

With clinicopathological factors, our study showed that p53 has a significant negative association with lymph node involvement $(\mathrm{P}=0.03)$, as well as, positive association with tumor grade $(\mathrm{p}=0.03)$, and in to some extent, with borderline significant, with tumor size $(\mathrm{p}=0.066)$ but not with histological type. From the literature, our results of p53 association with lymph nodes were compatible with study by Moradi-Marjaneh, et al., [55], they reported a significant reverse association between p53 and lymph node involvement while Tammim, et al., [40] reported that neither tumor grade and nor tumor size showed a correlation with p53 expression. Our results of p53 association with clinicopathological factors were incompatible, in to some extent, with studies $[41,54]$.

However, one of the relatively limits in this study, there is no molecular analysis, as well as, there is no similar study from Yemen which might confirm genetic variations.

In conclusion, study of ER, PR, Her2/neu and P53 in breast ductal carcinoma from Yamani women by IHC methods indicates that there are high rates of positive expression of theses markers. There is a significant correlation between the lymph node positive status and the levels of expression of ER and PR, but not with Her2/neu or P53. No statistically significant association was found between $E R, P R$, Her2/neu, P53 and tumor size or grade, with exception of P53 and tumor grade; however, it is statistically significant.

\section{ACKNOWLEDGMENTS}

None declared.

\section{CONFLICT OF INTEREST}

None declared.

\section{SUPPLEMENTARY MATERIAL}

Supplementary material is available on the publisher's web site along with the published article.

\section{REFERENCES}

[1] National Oncology Center: annual reports 2005-2007, Al-Jumhory Teaching Hospital, Sana'a, Yemen 2008.

[2] Parkin DM, Bray F, Ferlay J, Pisani P. Global cancer statistics, 2002. CA Cancer J Clin 2005; 55: 74-108.

[3] Allred DC, Wu Y, Mao S, et al. Ductal carcinoma in situ and the emergence of diversity during breast cancer evolution. Clin Cancer Res 2008; 14: 370-8.

[4] Mario CS, Jose' LP, Ricardo FS, Cla'udio GZ. Are the pure in situ breast ductal carcinomas and those associated with invasive carcinoma the same?. Appl Immunohistochem Mol Morphol 2010; 18: 51-4.

[5] Tang P, Hajdu SI, Lyman GH. Ductal carcinoma in situ: a review ofrecent advances. Curr Opin Obstet Gynecol 2007; 19: 63-7.

[6] Steinman S, Wang J, Bourne P, et al. Expression of cytokeratin markers, ER-alpha, PR, HER-2/neu, and EGFR in pure ductal carcinoma in situ (DCIS) and DCIS with co-existing invasive ductal carcinoma (IDC) of the breast. Ann Clin Lab Sci 2007; 37: 127-34. 
[7] Tang P, Wang X, Schiffhauer L, et al. Expression patterns of ERalpha, PR, HER-2/neu, and EGFR in different cell origin subtypes of high grade and non-high grade ductal carcinoma in situ. Ann Clin Lab Sci 2006; 36(2): 137-43.

[8] Pedrini JL, Pedrini M, Savaris RF, et al. Reassessing tumor markers in local recurrences of breast cancer: a new insight. Med Sci Monit 2004; 10: BR462-BR67.

[9] Croce MV, Isla-Larrain M, Remes-Lenicov $\mathrm{F}$, et al. MUC1cytoplasmic tail detection using CT33 polyclonal and CT2 monoclonal antibodies in breast and colorectal tissue. Histol Histopathol 2006; $21: 849-55$.

[10] Ferrero-Pous M, Trassard M, Le Doussal V, et al. Comparison of enzyme immunoassay and immunohistochemical measurements of estrogen and progesterone receptors in breast cancer patients. Appl Immunohistochem Mol Morphol 2001; 9: 267-75.

[11] Pinto AE, Andre S, Laranjeira C, et al. Correlations of cell cycle regulators (p53, p21, pRb and mdm2) and c-erbB-2 with biological markers of proliferation and overall survival in breast cancer. $\mathrm{Pa}-$ thology 2005; 37: 45-50.

[12] Jacobs TW, Gown AM, Yaziji H, et al. Specificity of Hercep test in determining HER-2/neu status of breast cancers using the United States food and drug administration-approved scoring system. J Clin Oncol 1999; 17: 1983-7.

[13] Pfister C, Moore L, Allard P, et al. Predictive value of cell cyclemarkers p53, MDM2, p21, and Ki-67 in superficial bladder tumor recurrence. Clin Cancer Res 1999; 5: 4079-84.

[14] Adebamowo CA, Famooto A, Ogundiran TO, Aniagwu T, Nkwodimmah C, Akang EE. Immunohistochemical and molecular subtypes of breast cancer in Nigeria. Breast Cancer Res Treat 2008; 110: 183-8.

[15] Sughayer MA, Al-khawaja MM, Massarweh S, Al-masri M. Prevalence of hormone receptors and HER2/neu in breast cancer cases in Jordan. Pathol Oncol Res 2006; 12(2): 83-6.

[16] Caraglia M, Santini D, Marra M, Vincenzi B, Tonini G, Budillon A. Emerging anti-cancer molecular mechanisms of aminobisphosphonates. Endocr Relat Cancer 2006; 13(1): 7-26.

[17] Harris L, Fritsche H, Mennel R, et al. American society of clinical oncology 2007 update of recommendations for the use of tumor markers in breast cancer. J Clin Oncol 2007; 25: 5287-312.

[18] Schorr MC, Pedrini JL, Savaris RF, Zettler CG. Are the pure in situ breast ductal carcinomas and those associated with invasive carcinoma the same?. Appl Immunohistochem Mol Morphol 2010; 18: 51-4.

[19] Schuetz CS, Bonin M, Clare SE, et al. Progression-specific genes identified by expression profiling of matched ductal carcinomas in situ and invasive breast tumors, combining laser capture microdissection and oligonucleotide microarray analysis. Cancer Res 2006; 66: 5278-86.

[20] Schorr MC, Pedrini JL, Savaris RF, Zettler CG. Are the pure in situ breast ductal carcinomas and those associated with invasive carcinoma the same?. Appl Immunohistochem Mol Morphol 2010; 18(1): 51-4.

[21] Hoque A, Menter DG, Sahin AA, et al. No increased Ki67 expression in ductal carcinoma in situ associated with invasive breast cancer. Cancer Epidemiol Biomarkers Prev 2001; 10: 153-4.

[22] Li CI, Malone KE, Daling JR. Differences in breast cancer hormone receptor status and histology by race and ethnicity among women 50 years of age and older. Cancer Epidemiol Biomark \& Prevent 2002; 11: 601-7.

[23] Amend K, Hicks D, Ambrosone CB. Breast cancer in AfricanAmerican women: differences in tumor biology from EuropeanAmerican women. Cancer Res 2006; 66(17): 8327-30.

[24] Telli ML, Kurian AW, Chang ET, Keegan TH, Ford JM, Gomez SL. Asian race and breast cancer subtypes: a study from the California Cancer Registry. J Clin Oncol 2008; 26: S 618.

[25] Stierer M, Rosen H, Weber R, Hanns H, Jurgen S, Heinz T. Immunohistochemical and biochemical measurement of estrogen and progesterone receptors in primary breast cancer correlation of histopathology and prognostic factors. Ann Surg 1993; 218(1): 1321.

[26] Li CI, Daling JR, Malone KE. Incidence of invasive breast cancer by hormone receptor status from 1992 to 1998 . JCO 2003; 21(1): 28-34.

[27] Hedayati-Moghadam MR. Correlation of HER2/neu overexpression, p53 protien accumulation and steroid receptor status with tumor characteristics: an Iranian study of breast cancer patients. Iranian J Publ Health 2008; 37(3): 19-28.

[28] Mudduwa LKB. Quick score of hormone receptor status of breast carcinoma: correlation with the other clinicopathological prognostic parameters. Ind J Path Microbiol 2009; 52(2): 159-63.

[29] Ayadi L, Khabir A, Amouri H, et al. Correlation of HER2 overexpression with clinicopathological parameters in Tunisian breast carcinoma. World J Surgical Oncol 2008; 6: 112.

[30] Rashed MM, Ragab NM, Galal MK. The association of HER2/neu over-expression in relation to p53 nuclear accumulation, hormonal receptor status and common clinicopathological prognostic parameters in a series of Egyptian women with invasive ductal carcinoma. Eur J Gen Med 2007; 4(2): 73-9.

[31] Yarney J, Vanderpuye V, Clegg JN. Hormone receptor and HER2 expression in breast cancers among Sub-Saharan African women. Breast J 2008; 14(5): 510-11.

[32] Azizun-Nisa, Bhurgri Y, Raza F, Kayani N. Comparison of ER, PR \& HER-2/neu(C-erb B2) reactive pattern with histologic grade, tumor size and lymph node status in breast cancer. Asian Pacific $\mathbf{J}$ Cancer Prev 2008; 9: 553-6.

[33] Ahmed HG, Safi SH, Shumo AI, Abdulrazig M. Expression of estrogen and progesterone receptors among sudanese women with breast cancer: immunohistochemical study. Sudan J Medical Stud 2007; 2 (1): 5-6.

[34] Almasri NM, Al-Hamad M. Immunohistochemical evaluation of human epidermal growth factor receptor 2 and estrogen and progesterone receptors in breast carcinoma in Jordan. Breast Cancer Res 2005; 7(5): R598-R604.

[35] Al-Moundhri M, Nirmala V, AL-Mawaly K, et al. Significance of p53, Bcl-2 , and HER2/neu protein expression in Omani Arab females with breast cancer. Pathol Oncol Res 2003; 9(4): 181-276.

[36] Lu X, Gu Y, Ding Y, et al. Correlation of ER, PR, HER-2/neu, p53, and VEGF with clinical characteristics and prognosis in Chinese women with invasive breast cancer. Breast J 2008; 14 (3): 308-10.

[37] Adebamowo CA, Famooto A, Ogundiran TO, Aniagwu T, Nkwodimmah C, Akang EE. Immunohistochemical and molecular subtypes of breast cancer in Nigeria. Breast Cancer Res Treat 2008; 110: 183-8.

[38] Cho EY, Choi YL, Han JA, Kim KM, Oh YL. Expression and amplification of HER2, EGFR and cyclin D1 in breast cancer: Immunohistochemistry and chromogenic in situ hybridization. Pathol Inte 2008; 58: 17-25.

[39] Chae BJ, Bae JS, Lee A, et al. P53 as a specific prognostic factor in triple-negative breast cancer. Jpn J Clin Oncol 2009; 39(4): 217-24

[40] Tammim L, Baker H, Sinowatz F. Immunohistochemical detection of p53 protein expression in breast cancer in young Kuwaiti women. Anticancer Res 2001; 21(1B): 743-8.

[41] Ihemelandu CU, Dewitty RL, Leffall LD, Suryanarayana SM, Frederick WA. Clinical significance ofp53 and bcl-2 protein coexpression phenotypes in molecular breast cancer subtypes of premenopausal and post-menopausal African-American women. Am Surg 2009; 75(9): 777-84.

[42] Olivotto IA, Truong PT, Speers $\mathrm{CH}$, et al. Time to stop progesterone receptor testing in breast cancer management. J Clin Oncol 2004; 22; (9): 1769-70.

[43] Colomer R, Beltran M, Dorcas J. It is not time to stop progesterone receptor testing in breast cancer. JCO 2005; 23(16): 3868-9.

[44] Chu KC, Anderson WF, Fritz A, Ries LA, Brawley OW. Frequency distributions of breast cancer characteristics classified by estrogen receptor and progesterone receptor status for eight Racial/Ethnic Groups. Cancer 2001; 92(1): 37-45.

[45] Dent R, Trudeau M, Pritchard KI, et al. Triple-negative breast cancer: clinical features and patterns of recurrence. Clin Cancer Res 2007; 13(15): 4429-34.

[46] Nishimura R, Arima N. Is triple negative a prognostic factor in breast cancer? Breast Cancer 2008; 15(4): 303-8.

[47] Vona-Davis L, Rose DP, Hazard H, et al. Triple-negative breast cancer and obesity in a rural appalachian population. Cancer Epidemiol Biomarkers Prev 2008; 17(12): 3319-24.

[48] Lund MJ, Butler EN, Bumpers HL, et al. High prevalence of triplenegative tumors in an urban cancer center. Cancer 2008; 113(3): 608-15.

[49] Stead LA, Lash TL, Sobieraj JE, et al. Triple negative breast cancers are increased in black women regardless of age or body mass index. Breast Cancer Res 2009; 11: R18. 
[50] Huang HJ, Neven P, Drijkoningen M, et al. Association between tumor characteristic and HER2/neu by immunohistochemistry in 1362 women with primary operable breast cancer. J Clin Pathol 2005; 58: 611-6.a

[51] Ratnatunga N, Liyanapathirana LVC. Hormone receptor expression and HER/2 amplification in breast carcinoma in a cohort of SriLankans. Papers 2007; 52(4): 133-6.

[52] Anim JT, John B, AbdulSathar SA, et al. Relationship between the expression of various markers and prognostic factors in breast cancer. Acta histochemica 2005; 107: 87-93.

[53] Ferrero JM, Ramaioli A, Formento JL, et al. P53 determination alongside classical prognostic factors in node-negative breast cancer: an evaluation at more than 10-year follow-up. Ann Oncol 2000; 11: 393-7.

[54] Climent MA, Segui MA, Peiro G, et al. Prognostic value of HER2/neu and p53 expression in node positive breast cancer. HER2/neu effect on adjuvant tamoxifen treatment. Breast J 2001; 10: $67-77$.

[55] Moradi-Marjaneh M, Homaei-Shandiz F, Shamsian SAA, Eftekhar-Zadeh MashhadiI, Hedayati-Moghadam MR. Correlation of HER2/neu over-expression, p53 protein accumulation and steroid receptor status with tumor characteristics: an Iranian study of breast cancer patients. Iranian J Publ Health 2008; 37(3): 19-28.

[56] Mohsin SK, Weiss H, Havighurst T, Clark GM, Berardo M, Roanh LD. Progesterone receptor by immunohistochemistry and clinical outcome in breast cancer: a validation study. Mod Pathol 2004; 17 1545-54.

[57] Yamashita $\mathrm{H}$, Toyama $\mathrm{T}$, Nishio $\mathrm{M}$, et al. $\mathrm{P} 53$ protein accumulation predicts resistance to endocrine therapy and decreased post relapse survival in metastatic breast cancer. Breast Cancer Res 2006; 8(4): R 48.

[58] Prati R, Apple SK, He J, Gornbein JA, Chang HR. Histopathologic characteristics predicting HER-2/neu amplification in breast cancer. Breast J 2005; 11(6): 433-9.

[59] Naeem M, Nasir A, Aman Z, Ahmad T, Samad A. Frequency of HER 2/neu receptor positivity and its association with other features of breast cancer. J Ayub Med Coll Abbottabad 2008; 20(3): 23-6.

[60] Hussein MR, Srah A, Abdulwahed AR. Alteration of estrogen receptors, progesterone receptors and c-erbB2 oncogene protein expression in ductal carcinomas of the breast. Cell Biol Int 2008; 32: 698-707.

(C) Ahmed et al.; Licensee Bentham Open.

This is an open access article licensed under the terms of the Creative Commons Attribution Non-Commercial License (http://creativecommons.org/licenses/by-nc/3.0/) which permits unrestricted, non-commercial use, distribution and reproduction in any medium, provided the work is properly cited. 